was determined by electrochemiluminescence. For all patients was started methotrexate (MT) therapy with a rapid increase in the dose to $30 \mathrm{mg}$ per week subcutaneously. If the MT was not effective enough, after 3 months a biological Disease-Modifying Anti-Rheumatic Drug (bDMARDs) was added to the therapy, predominantly TNF-alpha inhibitors. After 18 months, $10(45 \%)$ patients were in remission and low disease activity, $6(60 \%)$ of patients underwent MT therapy in combination with bDMARDs.

Results: In baseline CHF with preserved EF was revealed in 21 (95\%) patients, in 1 patient - CHF with reduced EF. After 18 months there was a positive dynamics of improvement of clinical symptoms, echocardiographic indicators (decrease the size of the left atrium (LA) and the index of end-systolic volume of LA, IVRT, E' LV), diastolic function of the left ventricle (LV). There was no decompensation of CHF. LV diastolic function normalized in 7 (32\%) patients who reached the target level of blood pressure, remission $(n=5)$ and low $(n=2)$ disease activity, mainly in the treatment of MT and bDMARDs. In patients with RA and CHF, the level of NT-proBNP decreased from 192.2 [151.4; $266.4]$ to 114.0 [90.4; 163.4] pg / ml ( $<<0.001)$, normalized in 16 of $22(73 \%)$ patients $(p<0.001)$ with remission or low RA activity. In $5(22 \%)$ patients, the clinical manifestations of CHF regressed, LV diastolic function and NT-proBNP level normalized.

Conclusion: In patients with early $\mathrm{RA}$ and $\mathrm{CHF}$ anti-rheumatic therapy improves the clinical course of CHF. There were an improvement in the clinical course of $\mathrm{CHF}$, diastolic function of the left ventricle and a decrease in NT-proBNP.

Disclosure of Interests: None declared

DOI: 10.1136/annrheumdis-2020-eular.4753

\section{AB0250 OSTEOPOROSIS, VERTEBRAL FRACTURES AND NON-ALCOHOLIC FATTY LIVER DISEASE IN RHEUMATOID ARTHRITIS: ARE THEY ASSOCIATED?}

H. Azzouzi ${ }^{1}$, B. Touil ${ }^{1}$, I. Linda ${ }^{1} .{ }^{1}$ Mohammed VI University Hospital, Rheumatology, Oujda, Morocco

Background: Non-alcoholic fatty liver disease (NAFLD) is a frequent finding in rheumatoid arthritis (RA). It has been advanced that NAFLD and vertebral fractures (VF) are associated in healthy men recently(1).

Objectives: The aim of this study was to evaluate NAFLD association with BMD and VF in RA population.

Methods: Cross-sectional study was made at our rheumatology department, patients with RA have been assessed for NAFLD with ultrasonography and osteoporosis (hip and lumber BMD) with DXA device. Patients with secondary liver disease (viral, alcoholic) were excluded. Data about osteoporosis risk factors, clinical features and laboratory tests (liver enzymes, lipid profile, hemoglobin, ferritin, etc) were collected. Anterior vertebral fractures (VF) were assessed by lateral spine radiographs. Comparison of patients with and without NAFLD was done by SPSS.20. Multiple regressions were made to explain osteoporosis and VF with models including NAFLD and other risk factors. Significance was defined by $p$ under 0.05 .

Results: We have included 172 RA patients, mean age was $55.4 \pm 11.9$ years. Ninety per cent were females. Their average BMI was $26.8 \pm 5.47$. Hypertension was diagnosed in $23.8 \%$ and $16.3 \%$ had diabetes. Forty per cent $(40.1)$ had osteoporosis, $27.3 \%$ (47) had NAFLD. RA patients with NAFLD were older $(p=0.04)$, obese $(p=0.003)$, frequently associated to diabetes $(p=0.02)$, Sjogren's disease $(p=0.001)$, higher total cholesterol $(p=0.02)$ and gamma-glutamyl transferase (GGT) $(p=0.002)$. Comparison tests did not reveal any associations with fractures, BMD or osteoporosis. In multiple regression models, patients with NAFLD and altered liver enzymes were associated to VF $(p=0.04, O R=4.7[1.05-21.69]$ but not to BMD when adjusted on age $(p=0.02)$, BMI $(p=0.02)$, diabetes, menopause and Sjogren's disease.

Conclusion: NAFLD was frequent among our RA patients and was associated to VF prevalence in this study but not to BMD.

References:

[1] Mantovani A, Dauriz M, Gatti D, Viapiana O, Zoppini G, Lippi G, et al. Systematic review with meta-analysis: non-alcoholic fatty liver disease is associated with a history of osteoporotic fractures but not with low bone mineral density. Aliment Pharmacol Ther. 2019 Feb;49(4):375-88

Disclosure of Interests: None declared

DOI: 10.1136/annrheumdis-2020-eular.4400

\section{$\mathrm{AB} 0251$ \\ SARCOPENIA IN MOROCCAN POPULATION WITH RHEUMATOID ARTHRITIS: PREVALENCE AND PREDICTIVE FACTORS}

E. Jalila ${ }^{1}$, H. Azzouzi ${ }^{1}$, I. Linda ${ }^{1} .{ }^{1}$ Mohamed VI University Hospital, Mohammed I University., Rheumatology, Oujda, Morocco
Background: Patients with rheumatoid arthritis (RA) were at risk for altered body composition with higher prevalence of sarcopenia compared to the general population. Low lean muscle mass may constitute an additional risk factor for altered bone density in RA patients.

Objectives: We aimed to study the prevalence of sarcopenia and to assess its predictive factors in Moroccan patients with RA.

Methods: We conducted a cross-sectional study over two months in our department of rheumatology. All RA patients fulfilled ACR/EULAR 2010 criteria. We performed a whole-body dual-energy X-ray absorptiometry (DXA) to measure lean mass, fat mass and bone mass in the whole body and body parts. The appendicular skeletal muscle mass was assessed using the sum of skeletal muscle mass in the arms and legs. The relative skeletal muscle mass index (RSMI) was calculated from the appendicular skeletal mass divided by the square of the patient's height $(\mathrm{kg} / \mathrm{m} 2)$. According to Baumgartner et al, sarcopenia was defined as a relative $\mathrm{SMI}<5.5 \mathrm{~kg} / \mathrm{m}^{2}$ on women and $<7.26 \mathrm{~kg} /$ $\mathrm{m}^{2}$ on men. Body mass index (BMI) was measured and patients were classified according to World Health Organization. Disease activity and functional disability were measured using the 28-joint Disease Activity Score (DAS28) with CRP and the Health Assessment Questionnaire (HAQ). Comorbidities and medication use including corticosteroids were also recorded. Data was entered and processed using the IBM SPSS Statistics 20. A univariate analysis as well as multivariate regressions were carried out to assess the association between sarcopenia and lumbar spine and femoral neck (FN) bone mineral density (BMD) and RA characteristics.

Results: We included 70 (87.5\%) women and 10 (12.5\%) men with a mean age of $53.59 \pm 10.96$ years old. They had a mean disease duration of $12.35 \pm 8.68$, a mean DAS 28 CRP of $2.64 \pm 1.34$, a mean HAQ of $0.94 \pm 0.63$ and a mean RSMI of $5.75 \pm 1.17$. Women had a mean RSMI of $6.33 \pm 1.04$ while men had a mean RSMI of $5.66 \pm 1.17$. The prevalence of sarcopenia in our population was $47.4 \%$ (37), of whom $81.1 \%$ (30) women.

In univariate regression analysis, sarcopenia was associated with normal BMI (OR: 8.59, 95\% CI [3.054-24.182], $p=0.000$ ), DAS 28 CRP (OR: 1.78 $95 \% \mathrm{Cl}[1.203-2.657], \mathrm{p}=0.004), \mathrm{HAQ}$ (OR: $2.15,95 \% \mathrm{Cl}[1.165-5.433$ ], $\mathrm{p}=0.019$ ), lumbar spine BMD (OR: $0.001,95 \% \mathrm{Cl}[0.00001-0.043], \mathrm{p}=$ 0.0004 ) and FN BMD (OR: $0.000006,95 \% \mathrm{Cl}[0.000-0.002], p=0,00008$ at right $\mathrm{FN}$ and $\mathrm{OR}: 0.00009,95 \% \mathrm{Cl}[0.000001-0.010], p=0.000$ at left $\mathrm{FN}$ respectively).

In multiple regression analysis, sarcopenia was associated with normal BMI (OR: 11.56, 95\% Cl [2.754-48.598]), $\mathrm{p}=0.001$ and FN BMD (OR: 0.00, 95\% C [0.000-0.084], $\mathrm{p}=0.006$ )

Conclusion: In the present study, sarcopenia was common among RA patients and associated with normal BMI and femoral neck BMD, emphasizing the importance of this modifiable risk factor. Further studies are needed to identify effective means to improve lean muscle mass in patients with RA.

References:

[1] Mochizuki T et al. Sarcopenia-associated factors in Japanese patients with rheumatoid arthritis: A cross-sectional study. Geriatr. Gerontol. Int. 2019;19 (9), 907-912

[2] Okano $T$ et al. Loss of lean body mass affects low bone mineral density in patients with rheumatoid arthritis -results from the TOMORROW studyModern Rheumatology. 2017;27(6):1-19.

[4] Peggy M. Cawthon. Assessment of Lean Mass and Physical Performance in Sarcopenia. Journal of Clinical Densitometry. 2015;18(4):467-71.

Disclosure of Interests: None declared

DOI: 10.1136/annrheumdis-2020-eular.4448

\section{$\mathrm{AB} 0252$ \\ ASSOCIATION OF FAT MASS AND ITS DISTRIBUTION WITH BONE MINERAL DENSITY FOR RHEUMATOID ARTHRITIS PATIENTS.}

O. Lamkhanat ${ }^{1}$, H. Azzouzi ${ }^{1}$, B. Touil ${ }^{1}$, I. Linda ${ }^{1} .{ }^{1}$ Centre Hospitalier Universitaire Mohammed VI, Rheumatology, Oujda, Morocco

Background: Bone mineral density (BMD) and body mass are closely associated. lean mass(LM) and fat mass(FM) account for approximately $95 \%$ of body mass[1].

Objectives: We aimed to study the association between body fat mass and its distribution with femoral and lumbar bone mineral density in rheumatoid arthritis (RA) patients

Methods: The present RA population-based cross sectionnel study done on 2019 was part of our rhumatology departement. Clinical data, femoral and lumbar BMD, body fat mass (BFM), android fat mass(AFM), gynoid fat mass (GFM), visceral fat mass (VFM) measured with dual energy X-ray absorptiometry (DXA Hologic () and results of laboratory tests were collected. Our statistical analysis was based on descriptive study and linear regression with SPSS20. 
Results: We included 73 RA patients witch mean age of $52.7+/-11.7$, their mean of body mass index was $26.6+/ 5.8$, mean of disease activity score was $2.6+/-0.94$ and the mean health assessment questionnaire was $1.14+/ 0.78$. In univariable linear regression, we found a significant association between femoral BMD and (BFM) ( $p=0.001$, béta=0.36, IC:[0.000003-0.00001]), (AFM) $(p=0.01$, béta $=0.29, I C:[0.00001,0.00008])$ and (GFM) $(p=0.001$, béta $=0.38$, $\mathrm{IC}=[0.000005-0.000088])$. There wasn't any association between (VFM) and femoral BMD. Also we have found a significant association between lumbar spine BMD and BFM ( $p=0.0002$, béta $=0.41, I C[0.000003-0.000011]), A F M(p=0.001$, béta $=0.38$, IC[0.000025-0.000094]), GFM( $\mathrm{p}=0.000018$, béta $=0.47$, IC[0.00003$0.00007]$ and VFM $(p=0.01$, béta $=0.28, I C[0.000027,0.000251])$. Adjusted on BFM, GFM, AFM and VFM in multiple regression analysis, it seems that the association between GFM, femoral BMD $(p=0.02$, béta $=0.38, I C[0.000005$, $0.000088]$. and lumbar spine $\operatorname{BMD}(p=0.01$, béta $=0.85, I C[0.000022,0.000168])$, was more significant.

Conclusion: The finding of this study confirmed previous studies partly, that genoid fat mass has a positive effect of lumbar and femoral BMD.

References: [1]S. Yang et al. Association between fat mass, lean mass, and bone loss: the Dubbo osteoporosis epidemiology study. International Osteoporosis Foundation and National Osteoporosis Foundation 2014, osteoporosis int. 2015; 26(4): 1381-6.

Disclosure of Interests: None declared

DOI: 10.1136/annrheumdis-2020-eular.4648

\section{AB0253 A REVIEW OF SMOKING CESSATION STRATEGIES AND LUNG CANCER SCREENING PRACTICES IN PATIENTS WITH RHEUMATOID ARTHRITIS}

M. A. Lopez-Olivo ${ }^{1}$, R. Volk ${ }^{1}$, K. J. Krause ${ }^{2}$, M. Suarez-Almazor ${ }^{1} .{ }^{1}$ The University of Texas, MD Anderson Cancer Center, Health Services Research, Houston, United States of America; ${ }^{2}$ The University of Texas, MD Anderson Cancer Center, Research Medical Library, Houston, United States of America

Background: Smoking rates among patients with rheumatoid arthritis (RA) exceed those reported in the general population. In addition, people with RA who smoke are more likely to develop lung cancer than smokers who do not have RA Objectives: To identify smoking cessation strategies and lung cancer screening practices in patients with $\mathrm{RA}$.

Methods: We conducted a review of the literature in electronic databases (i.e. PubMed, EMBASE, Cochrane, Scopus, and Web of Science) from inception until June 2019. We included studies that reported on the results of interventions for smoking cessation or lung cancer screening in patients with RA. We excluded case reports, reviews, guidelines, protocols, or studies on tobacco use not reporting interventions. We included studies published in abstract or full-text format. We extracted study and intervention characteristics including delivery format, timing and results.

Results: We retrieved 394 relevant citations and ultimately included 9 studies evaluating smoking cessation strategies, and one regarding lung cancer screening practices. Five studies were reported in abstract format. There were 3 studies conducted in the United Kingdom, and one each in Croatia, France, Ireland, New Zealand, Sweden, Spain and United States. Two studies were randomized control trials and the remaining were uncontrolled. Follow-up ranged between 1 month and 24 months, however, one study only reported data on the assessment immediately after the intervention. Sample sizes ranged between 20 and 185 current smokers. Smoking cessation strategies included: 1) brief advice and nicotine replacement therapy + smoking cessation counseling for 3 months; 2) information booklet on harms of smoking (i.e., impact on disease and treatment); 3) spoken information on harms of smoking (i.e., impact on disease and treatment) plus advice to quit smoking; 4) advice to quit smoking plus nicotine replacement; 5) smoking cessation support with contact every 4 weeks; 6) spoken information on harms of smoking (i.e., impact on disease and treatment) plus advice to quit smoking plus nurse telephone visit at $3^{\text {rd }}$ month; 6) staff driven tobacco QUIT line referral process; 7) multi-modality intervention with advise to quit smoking plus guidance on safe alcohol use plus dietary advise with booklet and swimming group. The lung cancer screening study reported on a program with nurse evaluation of comorbidities and risk factors, and recommendations for lung cancer screening with a chest $\mathrm{X}$-ray and smoking cessation. Most studies reported benefits when implementing a structured plan to educate, counsel, and offer pharmacological treatment to patients with RA.

Conclusion: There was large heterogeneity among studies in patient characteristics and interventions proposed, and outcomes. Only 2 studies were randomized clinical trials. Additional controlled studies are needed to determine best practices for smoking cessation and lung cancer screening in patients with RA. Disclosure of Interests: None declared

DOI: 10.1136/annrheumdis-2020-eular.4751

\section{AB0254 PATIENT CHARACTERISTICS, COMORBIDITIES, AND INFECTION OUTCOMES AMONG RHEUMATOID ARTHRITIS (RA) PATIENTS IN PUERTO RICO (PR)}

M. Suryavanshi ${ }^{1}$, S. Suri ${ }^{2}$, Y. Bao ${ }^{1}$, M. Ruiz ${ }^{3}$, V. Patel ${ }^{1}$, E. Madera-Miranda ${ }^{3}$. ${ }^{1}$ Bristol Myers Squibb, NJ, United States of America; ${ }^{2}$ Mu Sigma, Karnataka, India; ${ }^{3}$ Bristol Myers Squibb, Guaynabo, Puerto Rico

Background: Although the burden of comorbidities and infections in RA patients in the US is well established, ${ }^{1}$ there is an evidence gap for RA patients in the US territory of PR.

Objectives: To describe the patient demographics, clinical characteristics, and infection rates in patients with $\mathrm{RA}$ in $\mathrm{PR}$

Methods: $A$ retrospective cohort of adults age $\geq 18$ years from $P R$ with $\geq 2$ diagnosis of RA were identified using International Classification of disease codes (ICD-9 or ICD-10) on separate days from Jan 1, 2006 to June 30, 2018 using the Truven MarketScan $^{\mathrm{TM}}$ database. Patients were divided into three treatment cohorts: no treatment, conventional disease-modifying anti-rheumatic drugs (csDMARD) user and biologic DMARD (bDMARD) user. Patients in the no treatment group were followed from their first RA diagnosis date to the date of initiation of any DMARDs. The csDMARD users were followed from the initiation of csDMARD until the initiation of any bDMARD or targeted synthetic DMARDs (tsDMARDs). Patients were censored at the last observed medical claim if treatments were not initiated during follow-up. bDMARD users were followed from the date of initiation of bDMARD or tsDMARD until their last observed medical claim. Crude incidence rates /1000 person-years (PY) were reported for opportunistic infections (e.g. Mycobacterium, Cytomeglavirus, Candidiasis, and Chlamydial infections) and infections requiring hospitalisation. Results: Of the 623 patients in the cohort of RA patients from PR, majority were women $(75.4 \%)$, aged $41-64$ years $(67.1 \%)$, employed full time $(69.8 \%)$, with PPO health plan (89.4\%), and with mean length of follow-up of 5.77 years from index RA diagnosis. Our results shows that cardiovascular conditions (CVD, hypertension, and hyperlipidemia) were the most prevalent comorbidities in PR patients with RA (Table 1), followed by diabetes $(55.7 \%$ ) in the total RA patient population. The crude IR/1000 PY for opportunistic infections was 23.35 for patients in the no treatment cohort, 48.52 for patients in csDMARD, and 28.31 for bDMARD users. For hospitalized infections, the crude IR/1000 PY was 26.00 for patients in the no treatment cohort, 22.08 for csDMARD users, and 41.90 for bDMARD users.

Table 1. Patient Clinical Characteristics

\begin{tabular}{|c|c|c|c|c|c|c|c|c|}
\hline Patient Characteristics & $\begin{array}{l}\text { Total } \\
\text { Patients }\end{array}$ & & $\begin{array}{l}\text { No } \\
\text { Treatment }\end{array}$ & & $\begin{array}{l}\text { csDMARD } \\
\text { user }\end{array}$ & & $\begin{array}{l}\text { DMARD } \\
\text { ser }\end{array}$ & \\
\hline & $\mathrm{N}$ & $\%$ & $\mathrm{~N}$ & $\%$ & $\mathrm{~N}$ & $\%$ & $\mathrm{~N}$ & $\%$ \\
\hline & \multicolumn{7}{|c|}{ CCI Score } & 15.1 \\
\hline Mean (SD) & $\begin{array}{c}2.31 \\
(1.85)\end{array}$ & & $\begin{array}{c}2.39 \\
(1.82)\end{array}$ & & $1.85(1.47)$ & & $\begin{array}{c}2.57 \\
(2.41)\end{array}$ & \\
\hline \multicolumn{9}{|l|}{ Comorbidities } \\
\hline Total Patients & 571 & $91.7 \%$ & 486 & $80.2 \%$ & 130 & $77.4 \%$ & 76 & $80.9 \%$ \\
\hline Asthma & 170 & $29.8 \%$ & 125 & $25.7 \%$ & 33 & $25.4 \%$ & 25 & $32.9 \%$ \\
\hline Chronic Kidney Disease & 47 & $8.2 \%$ & 32 & $6.6 \%$ & 7 & $5.4 \%$ & 8 & $10.5 \%$ \\
\hline COPD & 138 & $24.2 \%$ & 108 & $22.2 \%$ & 22 & $16.9 \%$ & 16 & $21.1 \%$ \\
\hline Cardiovascular disease & 357 & $62.5 \%$ & 278 & $57.2 \%$ & 61 & $46.9 \%$ & 55 & $72.4 \%$ \\
\hline Hypertension & 447 & $78.3 \%$ & 371 & $76.3 \%$ & 87 & $66.9 \%$ & 63 & $82.9 \%$ \\
\hline Hyperlipidemia & 418 & $73.2 \%$ & 350 & $72.0 \%$ & 66 & $50.8 \%$ & 47 & $61.8 \%$ \\
\hline Malignancy & 124 & $21.7 \%$ & 101 & $20.8 \%$ & 18 & $13.9 \%$ & 20 & $26.3 \%$ \\
\hline Peripheral artery disease & 74 & $13 \%$ & 58 & $11.9 \%$ & 10 & $7.7 \%$ & 11 & $14.5 \%$ \\
\hline T2DM & 318 & $55.7 \%$ & 251 & $51.7 \%$ & 58 & $44.6 \%$ & 37 & $48.7 \%$ \\
\hline
\end{tabular}

Note: Comorbidities and $\mathrm{CCl}$ was calculated for patients during follow-up in respective cohort

Conclusion: Puerto Rican patients with RA have a significant burden of comorbidities, infections and hospitalisations. Trends indicate a variation in the burden by the type of treatment. Furthermore studies are warranted to better understand the potential healthcare implications of comorbidities in patients with RA.

References: [1]Yun, Huifeng et al. "Comparative risk of hospitalised infection associated with biologic agents in rheumatoid arthritis patients enrolled in Medicare." Arthritis \& Rheumatology 68, no. 1 (2016): 56-66.

Disclosure of Interests: Manasi Suryavanshi Consultant of: Bristol Myers Squibb, Sonick Suri Consultant of: Bristol Myers Squibb, Ying Bao Shareholder of: Bristol-Myers Squibb, Employee of: Bristol-Myers Squibb, Maribelis Ruiz Shareholder of: Bristol Myers Squibb, Employee of: Bristol Myers Squibb, Vardhaman PATEL Employee of: Bristol Myers Squibb, Eory Madera-Miranda Employee of: Bristol Myers Squibb

DOI: 10.1136/annrheumdis-2020-eular.3730 